\title{
Hyperuricaemia is associated with dyslipidemia but not HbA1c among type 2 diabetes mellitus patients in Botswana
}

\begin{tabular}{|c|c|}
\hline \multicolumn{2}{|c|}{ 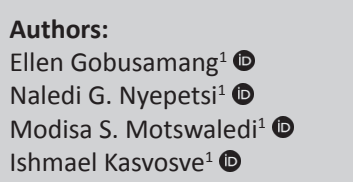 } \\
\hline \multicolumn{2}{|c|}{$\begin{array}{l}\text { Affiliations: } \\
\text { 'Department of Medical } \\
\text { Laboratory Sciences, Faculty } \\
\text { of Health Sciences, University } \\
\text { of Botswana, Gaborone, } \\
\text { Botswana }\end{array}$} \\
\hline \multicolumn{2}{|c|}{$\begin{array}{l}\text { Corresponding author: } \\
\text { Ishmael Kasvosve, } \\
\text { kasvosvei@ub.ac.bw }\end{array}$} \\
\hline \multicolumn{2}{|c|}{$\begin{array}{l}\text { Dates: } \\
\text { Received: } 07 \text { Feb. } 2018 \\
\text { Accepted: } 28 \text { June } 2019 \\
\text { Published: } 07 \text { Nov. } 2019\end{array}$} \\
\hline \multicolumn{2}{|c|}{$\begin{array}{l}\text { How to cite this article: } \\
\text { Gobusamang E, Nyepetsi NG, } \\
\text { Motswaledi MS, Kasvosve I. } \\
\text { Hyperuricaemia is associated } \\
\text { with dyslipidemia but not } \\
\text { HbA1c among type } 2 \\
\text { diabetes mellitus patients in } \\
\text { Botswana. Afr J Lab Med. } \\
\text { 2019;8(1), a786. https://doi. } \\
\text { org/10.4102/ajIm.v8i1.786 }\end{array}$} \\
\hline \multicolumn{2}{|c|}{$\begin{array}{l}\text { Copyright: } \\
\text { (c) 2019. The Authors. } \\
\text { Licensee: AOSIS. This wo } \\
\text { is licensed under the } \\
\text { Creative Commons } \\
\text { Attribution License. }\end{array}$} \\
\hline \multicolumn{2}{|l|}{ Read online: } \\
\hline 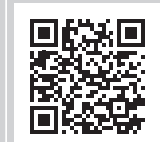 & $\begin{array}{l}\text { Scan this QR } \\
\text { code with your } \\
\text { smart phone or } \\
\text { mobile device } \\
\text { to read online. }\end{array}$ \\
\hline
\end{tabular}

Medical records and residual samples from 334 type 2 diabetes mellitus patients attending a clinic in Gaborone, Botswana, during the period September-December 2016 were analysed for the effects of hyperuricaemia on biochemical markers of adverse outcomes. The patients were stratified as having hyperuricaemia $(>400 \mu \mathrm{mol} / \mathrm{L})$ or normal serum uric acid $(\leq 400 \mu \mathrm{mol} / \mathrm{L})$. We compared glycated haemoglobin, triglycerides, low-density lipoprotein-cholesterol, highdensity lipoprotein-cholesterol, total cholesterol and serum creatinine between the two serum uric acid categories. Hyperuricaemia was detected in $28 \%$ of patients ( $95 \%$ confidence interval 23.1-32.9) and was associated with increased serum triglycerides, triglyceride to high-density lipoprotein-cholesterol ratio and creatinine concentration, but not with glycated haemoglobin.

Keywords: hyperuricaemia; diabetes mellitus; glycated haemoglobin; lipids; Africans.

\section{Introduction}

Epidemiologic studies suggest that hyperuricaemia plays a role in the aetiology and pathogenesis of a number of diseases including diabetes mellitus (DM).${ }^{1,2}$ Serum uric acid (SUA) has a putative role in the development of cardiovascular disease. ${ }^{3,4}$ In a recent study conducted in South Africa, hyperuricaemia was associated with an increased risk of mortality among acute myocardial infarction patients. ${ }^{5}$ However, it remains unclear whether increased SUA concentration contributes to the aetiology or if it is a consequence of these conditions.

The role of SUA in type 2 diabetes mellitus (T2DM) is inconclusive. However, hyperuricaemia is associated with obesity and insulin resistance, ${ }^{6}$ and cross-sectional data have shown that hyperuricaemia is prevalent among T2DM patients. ${ }^{7}$ Other studies have also reported that hyperuricaemia increases the risk of T2DM. $8,9,10$ In a meta-analysis of 11 cohort studies, participants with hyperuricaemia had a $17 \%$ increased risk of developing diabetes per $1 \mathrm{mg} / \mathrm{dL}$ increase in SUA concentration. ${ }^{9}$ In another meta-analysis of eight prospective cohort studies, a $1 \mathrm{mg} / \mathrm{dL}$ increase in SUA resulted in a $6 \%$ increase in the risk of incident T2DM. ${ }^{8}$ Other studies have reported that hyperuricaemia predisposes individuals to the development of DM complications. ${ }^{11}$

Among DM patients, poor glycaemic control increases the risk of microvascular complications. ${ }^{12}$ The measurement of glycated haemoglobin $\left(\mathrm{HbA}_{1 \mathrm{c}}\right)$ and lipids are used to monitor $\mathrm{DM}$ patients, and adverse changes are associated with the risk of $\mathrm{DM}$ complications. $\mathrm{HbA}_{1 \mathrm{c}}$ is a biochemical indicator of chronic glycaemia, and high values indicate poor control. ${ }^{13}$ The determination of total cholesterol, low-density lipoprotein (LDL) and high-density lipoprotein (HDL) cholesterol, and triglycerides provide valuable information for the prediction of coronary heart disease. Triglyceride concentration has an inverse relationship with HDL cholesterol concentration in DM patients. ${ }^{13}$ Both hypertriglyceridemia and low serum HDL cholesterol concentration independently increase the risk of developing coronary heart disease. ${ }^{13}$

Findings on the role of SUA in the pathogenesis of DM are inconsistent, and studies on associations between hyperuricaemia and the development of microvascular diseases among DM patients in African populations are lacking. In this study we determined the prevalence of hyperuricaemia and its association with $\mathrm{HbA}_{1 \mathrm{c}}$ and lipids in T2DM patients in Botswana.

\section{Methods}

\section{Ethical considerations}

The study was approved by the University of Botswana's institutional review board, the Ministry of Health and Wellness Health Research Unit (permit number HPDME: 13/18/1 Vol X [619]) and 
the Research and Ethics Committee of Princess Marina Hospital (permit number PMH 5/79 [268-2-2016]). No individual consent was obtained from the patients.

\section{Study population}

We conducted a cross-sectional study of residual samples from 334 T2DM patients attending a DM clinic in Gaborone City, during the period September-December 2016. The criteria for inclusion were age $\geq 18$ years and a known history of T2DM. Minors (<18 years) with T2DM were excluded from the study. The samples enrolled in the study were collected as part of clinical care and were de-identified prior to inclusion in the study, as recommended in the International Organization for Standardization's 15189 standard. The clients' identities were not revealed to study staff and confidential information was only made accessible to authorised persons.

\section{Laboratory investigations}

Laboratory tests were performed on AU480 Chemistry Analyzer (Beckman Coulter Inc, Brea, California, United States). In some cases, the sample volume was insufficient to perform all the tests or the data were missing from the patient's records. The analyser was calibrated and samples processed according to the manufacturer's instructions using reagents provided by the manufacturer. Serum uric acid was measured using the uricase/peroxidase enzymatic method, and hyperuricaemia was defined as SUA $>400 \mu \mathrm{mol} / \mathrm{L}$. This cutoff is the upper reference limit used to define hyperuricaemia in Botswana. $\mathrm{HbA}_{1 \mathrm{c}}$ was measured using a latex agglutination assay. Briefly, a synthetic polymer containing multiple copies of the immunoreactive portion of $\mathrm{HbA}_{1 \mathrm{c}}$ agglutinates with latex coated with $\mathrm{HbA}_{1 c}$-specific mouse monoclonal antibodies. Total cholesterol, HDL cholesterol, LDL cholesterol and triglycerides were determined by routine enzymatic methods. Creatinine was measured using a kinetic modification of the Jaffe procedure. ${ }^{14}$

\section{Statistical analysis}

The results were analysed using the Statistical Package for Social Sciences version 24 statistical software (IBMCorporation, New York City, New York, United States). All quantitative variables were expressed as mean \pm standard deviation or median with interquartile range (IQR). Categorical variables were expressed as proportions with estimated $95 \%$ confidence intervals (CI). Comparisons of $\mathrm{HbA}_{1 \mathrm{c}}$ concentration according to sex or SUA categories were conducted using an independent samples $t$-test, or the Mann-Whitney test was used to compare medians for non-parametric data. Results were considered statistically significant if $p<0.05$. Box-and-whisker plots were used to show differences in serum creatinine concentration and $\mathrm{HbA}_{1 \mathrm{c}}$ according to uric acid category.

\section{Results}

Samples from 334 patients (236 women) with T2DM of unknown duration were studied. Ninety-two patients $(28 \%$, 95\% CI 23.1-32.9) had hyperuricaemia and the prevalence was
TABLE 1: Comparison of laboratory characteristics according to serum uric acid categories in type 2 diabetes mellitus patients receiving treatment in Gaborone, Botswana, September-December 2016.

\begin{tabular}{lccc}
\hline Parameter & $\begin{array}{c}\text { Normal uric acid } \\
\boldsymbol{n}=\mathbf{2 4 2}\end{array}$ & $\begin{array}{c}\text { Hyperuricaemia } \\
\boldsymbol{n}=\mathbf{9 2}\end{array}$ & $\boldsymbol{p}$ \\
\hline Age, years & - & - & 0.235 \\
Mean \pm standard deviation & $56 \pm 14$ & $58 \pm 11$ & \\
Glycated haemoglobin & $7.4 \dagger$ & $7.1 \Phi$ & 0.379 \\
$\%$ & $6.3-9.3$ & $6.4-8.9$ & \\
Creatinine concentration & 62 & 78 & $<0.001$ \\
$\mu$ mol/L & $(52-73)$ & $(61-115)$ & \\
Triglyceride concentration & $1.72 \dagger$ & $1.99 \dagger \dagger$ & 0.032 \\
mmol/L & $1.19-2.52$ & $1.48-2.57$ & \\
LDL cholesterol, mmol/L & $2.58 \pm 0.87 \dagger$ & $2.70 \pm 0.96 \dagger \dagger$ & 0.321 \\
HDL cholesterol & $1.04 \S$ & $0.99 \dagger \dagger$ & 0.090 \\
mmol/L & $0.90-1.28$ & $0.86-1.19$ & \\
Total cholesterol, mmol/L & $4.57 \pm 1.22 \dagger$ & $4.72 \pm 1.37 \dagger \dagger$ & 0.371 \\
Triglyceride/HDL cholesterol & $1.71 \S$ & $1.89 \dagger \dagger$ & 0.021 \\
Ratio & $(1.00-2.44)$ & $(1.33-2.79)$ & \\
Uric acid concentration, $\mu$ mol/L & $298 \pm 65$ & $481 \pm 79$ & $<0.001$ \\
\hline
\end{tabular}

Note: In some cases, sample volume was insufficient to perform all the tests or the data were missing from the patient's records.

Normal uric acid was defined as $\leq 400 \mu \mathrm{mol} / \mathrm{L}$ and hyperuricaemia as serum uric acid $>400$ $\mu \mathrm{mol} / \mathrm{L}$. Values are expressed as mean \pm standard deviation or median with interquartile range.

LDL, low-density lipoprotein; HDL, high-density lipoprotein.

$\dagger, n=234$.

$\$ n=226$.

$\S, n=206$.

$\uparrow, n=90$.

$\dagger, n=82$.

$+4, n=74$.

comparable between sexes (25\% [95\% CI 19.4-30.6] in women compared to $33 \%$ [95\% CI 23.5-42.5] in men, $p=0.182$ ). $\mathrm{HbA}_{1 \mathrm{c}}$ levels were comparable between SUA categories; median 7.1\% (IQR 6.4-8.9) in T2DM patients with hyperuricaemia compared to median 7.4\% (IQR 6.3-9.3) in T2DM patients with normalSUA, $p=0.379$ (Table 1). Similarly, hyperuricaemia had no effect on total and LDL cholesterol levels, $p \geq 0.321$. There was a tendency for lower HDL cholesterol among patients with hyperuricaemia, $p=0.090$. Median triglyceride levels were higher among patients with hyperuricaemia (1.99 $\mathrm{mmol} / \mathrm{L}$ [IQR 1.48-2.57] vs $1.72 \mathrm{mmol} / \mathrm{L}$ [IQR 1.19-2.57], $p=$ 0.032); similarly, T2DM patients with hyperuricaemia had higher ratios of triglycerides to HDL cholesterol (median: 1.89 [IQR 1.33-2.79]) compared to T2DM patients with normal SUA concentration (median: 1.71 [IQR 1.00-2.44], $p=0.021$ ). Hyperuricaemia was associated with higher median creatinine concentration, $78 \mu \mathrm{mol} / \mathrm{L}$ (IQR 61-115) vs $62 \mu \mathrm{mol} / \mathrm{L}$ (IQR $52-73$ ) in patients with normal uric acid, $p<0.001$ (Figure 1).

\section{Discussion}

The prevalence of hyperuricaemia among T2DM patients in Botswana is high and is comparable to findings in North Africa. ${ }^{15}$ In our study, hyperuricaemia was not associated with poor glycaemic control as measured by $\mathrm{HbA}_{1 c}$. This is in contrast to data from the National Health and Nutrition Examination Survey III conducted nationwide in the United States. ${ }^{16}$ Our data corroborates findings from another study conducted on a cohort of newly diagnosed T2DM patients in China that reported no relationship between SUA and $\mathrm{HbA}_{1 \mathrm{c}}$ after adjusting for insulin concentration. ${ }^{17}$ 


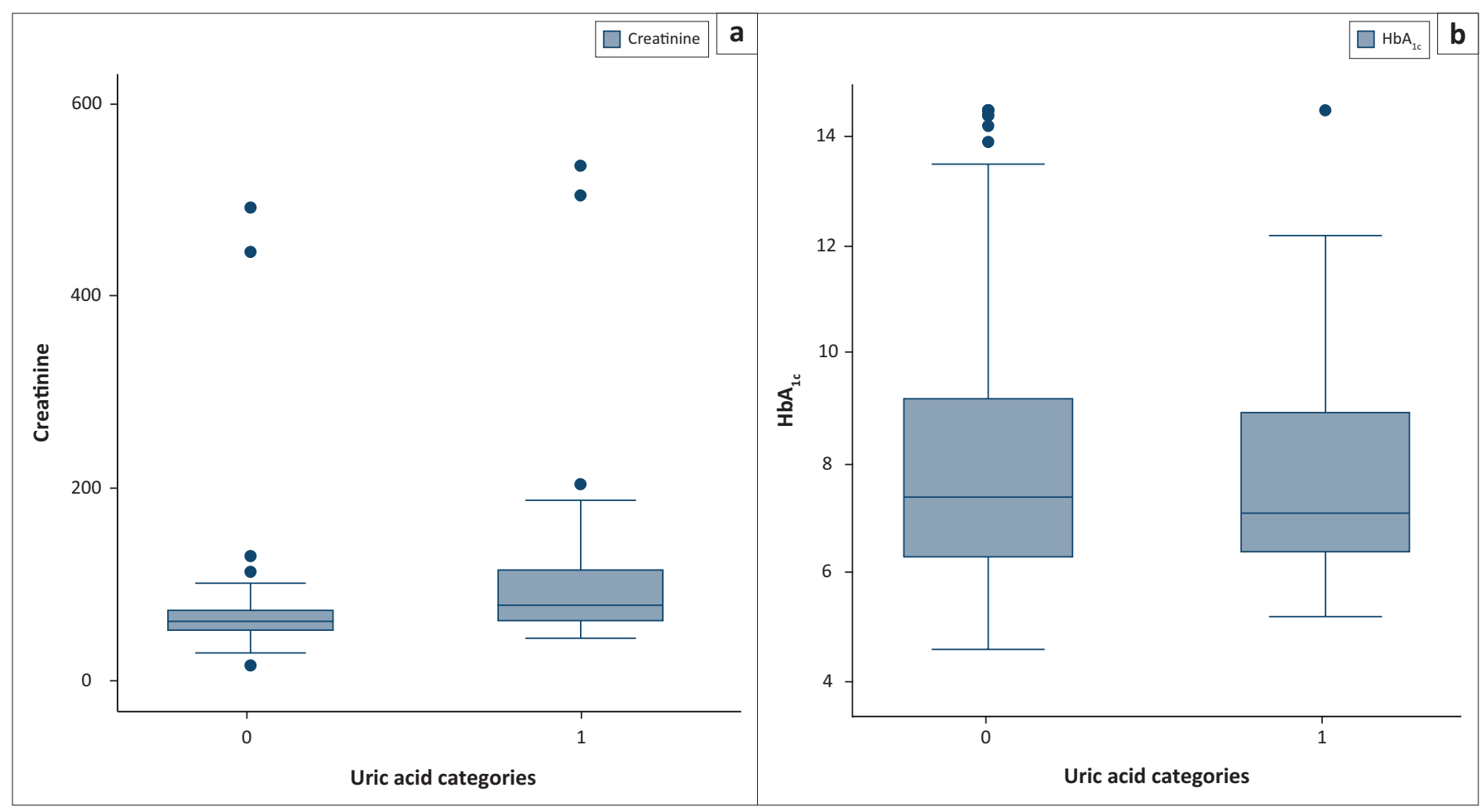

Uric acid categories: $0=$ normal uric acid concentration ( $\leq 400 \mu \mathrm{mol} / \mathrm{L}$ ); $1=$ hyperuricaemia (> $400 \mu \mathrm{mol} / \mathrm{L}$ ). Hyperuricaemia was associated with higher median creatinine concentration $78 \mu \mathrm{mol} / \mathrm{L}$ (interquartile range 61-115) in patients with hyperuricemia versus $62 \mu \mathrm{mol} / \mathrm{L}$ (interquartile range $52-73$ ) in patients with normal uric acid, $p<0.001$. Glycated haemoglobin was comparable between the two groups.

$\mathrm{HBA}_{1,}$, haemoglobin.

FIGURE 1: Comparison of (a) serum creatinine concentration and (b) glycated haemoglobin ( $\mathrm{HbA}_{1 \mathrm{c}}$ ) according to uric acid category in type 2 diabetes mellitus patients receiving treatment in Gaborone, Botswana, September-December 2016.

Lipids are a risk factor for cardiovascular disease..$^{13}$ In our study, T2DM patients with hyperuricaemia had significantly higher triglyceride concentrations and triglyceride to HDL cholesterol ratios. It has been suggested that a high triglyceride to HDL cholesterol ratio is a risk factor for coronary heart disease. ${ }^{18}$ The triglyceride to HDL cholesterol ratio can be used to predict the presence and degree of coronary atherosclerosis. ${ }^{19}$ Although high triglyceride to HDL cholesterol ratio has been reported to be a marker of insulin resistance, ${ }^{20}$ a study of African Americans did not corroborate this finding. ${ }^{21}$ Other lipids were not associated with hyperuricaemia in our study.

Hyperuricaemia was associated with an increased creatinine concentration. Although hyperuricaemia may simply be a marker of renal disease, there are studies which suggest that elevated SUA levels might contribute to the development and progression of renal dysfunction. ${ }^{3}$ Recently (2014), Toda et al. reported that hyperuricaemia was an independent risk factor for the development of chronic kidney disease, ${ }^{22}$ and in studies in Japan, elevated baseline SUA and increases in SUA increased the risk of developing chronic kidney disease. ${ }^{23}$ In another study, hyperuricaemia was associated with incident diabetic retinopathy among male patients with T2DM. ${ }^{24}$

\section{Limitations}

We acknowledge that missing data on DM duration is a limitation to the interpretation of our findings, as the evolution of nephropathy and microvascular diseases may be influenced by the duration of DM. Adjusting for the duration of $\mathrm{T} 2 \mathrm{DM}$ and the severity of DM might have sharpened our findings. In a study by Korpachev et al. in 2009, hyperuricaemia with decreased uric acid excretion was characteristic of severe DM, with a reduced kidney filtration rate. ${ }^{25}$ Conditions that reduce erythrocyte survival time may affect $\mathrm{HbA}_{1 \mathrm{c}}$ values. Although we did not screen for the effect of haemoglobinopathies or malaria on $\mathrm{HbA}_{1 c^{\prime}}$ it is unlikely that these conditions were confounders in our study. Malaria transmission in southern Botswana is low to absent, and there is no literature on haemoglobinopathy in Botswana.

\section{Conclusion}

In conclusion, hyperuricaemia was prevalent among T2DM patients in our study and was associated with elevated triglyceride concentrations, a high triglyceride to HDL cholesterol ratio and elevated serum creatinine concentration, but it was not associated with $\mathrm{HbA}_{1 \mathrm{c}}$ concentration. As recommended elsewhere, the monitoring of T2DM should include the measurement of SUA and the institution of interventions that lower SUA. ${ }^{3}$

\section{Acknowledgements}

We would like to thank the laboratory staff of the National Health Laboratory Service and Lancet Laboratories for providing the serological and molecular testing.

\section{Competing interests}

The authors have declared that no competing interests exist. 


\section{Authors' contributions}

E.G. and I.K. were responsible for the conceptualisation, experimental design, data acquisition, analysis, interpretation of data and writing of the manuscript. N.G.N. and M.S.M. contributed to the experimental design and revising the manuscript for important intellectual content. All authors read and approved the final manuscript.

\section{Sources of support}

This research did not receive any specific grant from funding agencies in the public, commercial or not-for-profit sectors.

\section{Data availability statement}

Data sharing is not applicable to this article as no new data were created or analysed in this study.

\section{Disclaimer}

The views and opinions expressed in this article are those of the authors and do not necessarily reflect the official policy or position of any affiliated agency of the authors.

\section{References}

1. Kivity S, Kopel E, Steinlauf S, et al. The association between serum uric acid and diabetes mellitus is stronger in women. J Women Health. 2013; 22(9):782-789. https://doi.org/10.1089/jwh.2012.4043

2. Freedman DS, Williamson DF, Gunter EW, et al. Relation of serum uric acid to mortality and heart disease. The NHANES I Epidemiologic follow-up study. Am J Epidemiol. 1995;141:637-644. https://doi.org/10.1093/oxfordjournals.aje.a117479

3. Martinez-Quintana E, Tugores A, Rodriguez-González F. Serum uric acid levels and cardiovascular disease: The Gordian knot. J Thorac. 2016;8(11):E1462-E1466. https://doi.org/10.21037/jtd.2016.11.39

4. Kivity S, Kopel E, Maor E, et al. Association of serum uric acid and cardiovascular disease in healthy adults. Am J Cardiol. 2013;111:1146-1151. https://doi. org/10.1016/j.amjcard.2012.12.034

5. Ranjith N, Myeni NN, Sartorius B, et al. Association between hyperuricemia and major adverse cardiac events in patients with acute myocardial infarction. Metab Syndr Relat Disord. 2017; 15:18-25. https://doi.org/10.1089/met.2016.0032

6. Baker JF, Krishnan E, Chen L, et al. Serum uric acid and cardiovascular disease: Recent developments, and where do they leave us? Am J Med. 2005;118:816-826. https://doi.org/10.1016/j.amjmed.2005.03.043

7. Heinig $M$, Johnson RJ. Role of uric acid in hypertension, renal disease, and metabolic syndrome. Cleve Clin J Med. 2006;73:1059-1064.
8. Lv Q, Meng XF, He FF, et al. High serum uric acid and increased risk of type 2 diabetes: A systematic review and meta-analysis of prospective cohort studies. PLoS One. 2013;8(2):e56864. https://doi.org/10.1371/journal.pone.0056864

9. Kodam S, Saito K, Yachi Y, et al. Association between serum uric acid and development of type 2 diabetes. Diabetes Care. 2009;32:1737-1742. https://doi. org/10.2337/dc09-0288

10. Jia Z, Zhang $X$, Kang $S$, et al. Serum uric acid levels and incidence of impaired fasting glucose and type 2 diabetes mellitus: A meta-analysis of cohort studies. Diabetes Res Clin Pract. 2013;101:88-96. https://doi.org/10.1016/j.diabres.2013.03.026

11. Lee JJ, Yang IH, Kuo HK, et al. Serum uric acid concebtration is associated with worsening in severity of diabetic nephropathy among type 2 diabetic patients in Taiwan - a 3-year prospective study. Diabetes Res Clin Pract. 2014;106 (2):366372. https://doi.org/10.1016/j.diabres.2014.07.027

12. Klein R, Klein BE, Moss SE. Relation of glycemic control to diabetic microvascular complications in diabetes mellitus. Ann Intern Med. 1996;124:90-96. https://doi. org/10.7326/0003-4819-124-1_part_2-199601011-00003

13. NIH Consensus Conference: Triglyceride, high-density lipoprotein and coronary heart disease. JAMA. 1993;269:505-510.

14. Bowers LD, Wong ET. Kinetic serum creatinine assays. II. A critical evaluation and review. Clin Chem. 1980;26 (5):555-561.

15. Fouad M, Fathy $\mathrm{H}$, Zidan A. Serum uric acid and its association with hypertension, early nephropathy and chronic kidney disease in type 2 diabetic patients. J Bras Nefrol. 2016;38:403-410. https://doi.org/10.5935/0101-2800.20160065

16. Bandaru P, Shankar A. Association between serum uric acid levels and diabetes mellitus. Int J Endocrinol. 2011;604-715. https://doi.org/10.1155/2011/ 604715

17. Cui $\mathrm{Y}, \mathrm{BuH}, \mathrm{MaX}$, et al. The relation between serum uric acid and $\mathrm{HbA}$ is dependent upon hyperinsulinemia in patients with newly diagnosed type 2 diabetes mellitus. J Diabetes Res. 2016:7184123. https://doi.org/10.1155/2016/7184123

18. Da Luz PL, Favarato D, Faria-Neto Jr JR, et al. High ratio of triglycerides to HDLcholesterol ratio predicts extensive coronary disease. Clinics. 2008;63:427-432. https://doi.org/10.1590/S1807-59322008000400003

19. Gaziano JM, Hennekens $\mathrm{CH}$, O'Donnell CJ, et al. Fasting triglycerides, high density lipoprotein, and risk of myocardial infarction. Circulation. 1997; 96:2520-2525. https://doi.org/10.1161/01.cir.96.8.2520

20. Hadaeghi F, Khalili D, Ghasemi A, et al. Triglyceride/HDL-cholesterol ratio is an independent predictor for coronary heart disease in a population of Iranian men. Nutr Metab Cardiovsac Dis. 2009;19(6):401-408. https://doi.org/10.1016/j. numecd.2008.09.003

21. Sumner AE, Finley KB, Genovese DJ, et al. Fasting triglyceride and the triglyceride-HDL cholesterol ratio are not markers of insulin resistance in African Americans. Arch Intern Med. 2005;165(12):1395-1400. https://doi.org/10.1001/archinte.165.12.1395

22. Toda $A$, Ishizaka $Y$, Tani $M$, et al. Hyperuricemia is a significant risk factor for the onset of chronic kidney disease. Nephron Clin Pract. 2014;126(1):33-38. https:// doi.org/10.1159/000355639

23. Kuwabara M, Bjornstad $\mathrm{P}$, Hisatome I, et al. Elevated serum uric acid level predicts rapid decline in kidney function. Am J Nephrol. 2017;45:330-337. https://doi. org/10.1159/000464260

24. Kuwata $H$, Okamura $S$, Hayashino $Y$, et al. Serum uric acid levels are associated with increased risk of newly developed diabetic retinopathy among Japanese male patients with type 2 diabetes: A prospective cohort study (diabetes distres and care registry at Tenri [DDCRT 13]). Diabetes Metab Res Rev. 2017;33(7) https://doi.org/10.1002/dmrr.2905

25. Korpachev VV, Hurina NM, Korpacheva TI, et al. Peculiarities of uric acid balance disorders in patients with type 2 diabetes and metabolic syndrome. Fiziol $\mathrm{Zh}$ 2009;55(3):133-140 